\title{
Impact of Occupational Stress on Nurses' Job Performance According to Nurses Perception
}

\author{
Haneen Al- Nuaimi ${ }^{1}$, Mohammed ALBashtawy ${ }^{2}$ Jamal Qaddumi $^{3}$, Mohammed Baqir ${ }^{4}$, \\ Mohammad Suliman ${ }^{5}$, Asem Abdalrahim ${ }^{6}$, Abdullah Alkhawaldeh ${ }^{7}$ \\ ${ }^{I} R N$, Master Student, Critical Care Nursing, Princess Salma Faculty of Nursing, AL al-Bayt University, Mafraq, \\ Jordan, ${ }^{2}$ Professor, Princess Salma Faculty of Nursing, AL al-Bayt University, Mafraq, Jordan, ${ }^{3}$ Associate \\ Professor, Faculty of Medicine and Health Sciences, An-Najah National University, Nablus-Palestine, ${ }^{4}$ Assistance \\ Professor, Faculty of Nursing, Baghdad University, Baghdad, Iraq, ${ }^{5}$ Associate Professor, Princess Salma Faculty \\ of Nursing, AL al-Bayt University, Mafraq, Jordan, ${ }^{6}$ Assistance Professor, Princess Salma Faculty of Nursing, \\ AL al-Bayt University, Mafraq, Jordan, ${ }^{7}$ Assistance Professor, Princess Salma Faculty of Nursing, AL al-Bayt \\ University, Mafraq, Jordan
}

\begin{abstract}
Nursing isa riskyprofession. Nurses faces a lot of stressors. The purpose of paper to review the previous researches discussed the impact of nurse's job stress on nurses' performance. This paper is used the electronic searches: Google scholar, EBSCO and CINAHL.This paper discussed the level of stressand different types of stressors among nurses in different setting. And,the type of relations between job stress, clinical performance, job satisfaction, quality of life, physical and mental health of nurses were discussed.
\end{abstract}

Keywords: nurses, job stress, occupational stress, job performance, and work stress.

\section{Introduction}

Nursing is very sensitive and demanding occupation, and nurses exposed to the different situations that influence their physical and mental health ${ }^{(1)}$. Nurses are exposed to the life-threatening injuries and diseases due to their riskyprofession. Nurses have a compressed program, complex hierarchy of power, having human health responsibility,exposed to people who are dying,face emergency situations, and deal with complex equipment's ${ }^{(1)}$. Occupational stress in nursing is very common, that is affect physical, mental, and social equilibrium. These factors lead to the high level of stress among nurses, which lead to negative consequences such as: delay or absence on work, depression, fatigue, low job performance,that lead to low quality of care $^{(1)}$.

\section{Corresponding Author:}

Abdullah Alkhawaldeh, $\mathrm{PhD}$,

Assistance Professor, Princess Salma Faculty of Nursing, AL al-Bayt University, Mafraq, Jordan. Email: dr-abd@aabu.edu.jo, abdo_752012@yahoo.com
Job stress define as "an individual's response toexternal stimuli in the environment" (2). Also, occupational stress was defined as "harmful physicaland emotional responses that occur when the requirements ofa job do not match the resources, capabilities and needs of theworker" (3). Job stress lead to the negative effect on individual physiology, psychology, and behaviors (such as, job performance). Stress divided into two dimensions: challenge stress, that nurses can overcome it, and used it to develop their career, like: job load, and time urgency, and hindrance stress, that nurses can't overcome it, and negatively affect their career development, like: work insecurity, and role conflict ${ }^{(2)}$.

Occupational stress has a financial burden on health care systems, World Health Organization (WHO) estimated the cost of work stress and its related problems about $\$ 150$ billion annually ${ }^{(4)}$.Besides that, low job performance and reduced quality of nursing services, are affect patient safety ${ }^{(3)}$.According to the American Institute of Stress Work, stress is responsible about $80 \%$ of work injuries and $40 \%$ of workplace turnover ${ }^{(5)}$.Job or work stress is responsible about $70 \%$ of absenteeism, 
and wasteabout $10 \%$ of country gross domestic product. It estimated that $93 \%$ of nurses under stress factors in their work ${ }^{(6)}$.

Job performance was defined as " the actions and behaviors ofindividuals in roles and responsibilities of their work that contributeto organizational goals"(3). Developing job performance of nurses lead to organizational success ${ }^{(7)}$. Occupational stress may be caused by poor management, poor working conditions, and lack of support from supervisors and colleagues, hospitals administrations can be enhanced nurse's performance by develop strategies to improve work environment that reflect not only on performance of nurses, but also on the quality of nursing services provided (4).

Thisreview paperaimed to search the impact of occupational stress on the job performance of the nurses.

\section{Method}

Search methods: The electronic searching was conducted in a different database: Google scholar, EBSCO, and CINAHL. Key search terms used: nurses, job stress, occupational stress, job performance, and work stress.

The studies that focused on the topic of occupational stress,were published in English between 2015 and 2020 were included in the review. While, studies published before 2015 were excluded.

Search Outcomes: The result of searching literature yields 30 studies for review, 16 studies excluded when read the title, and 4 studies excluded when reading the abstracts, and 10 studies were included in the review.

\section{Discussion}

Thereare two types of stress which are strongly correlated. The challenge stress is positively associated with job performance and public service motivations (PSM). While, hindrance stress is negatively associated with job performance and public service motivation ${ }^{(2,8)}$.

A study was conducted to compare if there is a differences between job performance, occupational stress, and the general health between nurses in psychiatric departments and nurses in emergency departments in Milad, Erfanian, Iranian in Tehran, Iran.
The data revealed that job stress, job performance, and general health among nurses in both departments are vary. Psychiatric department nurses job performance, stress, and general health are greater than emergency department nurses, that means psychiatric nurses are more affected ${ }^{(1)}$. Another studywas conducted to assess occupational stress, job performance, and job satisfaction in three teaching hospitals. According to study, there is significant inverse relationship between occupational stress and job performance, and job satisfaction. Nurses have moderate level of stress and job satisfaction, and high level of job performance. There is no relation between job satisfaction and job performance. Besides that, male nurses, single nurses, and high educational level have more job satisfaction ${ }^{(3)}$.

The effect of occupational stress among nurses is become more crucial in pediatric department and neonatal intensive care units. A studyassessed the relationship between occupational stress among nurses working in pediatric wards and neonate intensive care units and job performance. The results showed that all nurses have high level of stress. Lack of aid and resources, work atmosphere in pediatric wards and NICU's consider high job stressors among nurses, whereas hospital characteristics consider low job stressor. Results also showed no relationship between occupational stressors and nurses job performance in pediatric ward and NICU's in Khartoum hospitals. Managerial support and behaviors affect job performance ${ }^{(4)}$.

The relation between job stress and head nurses job performance was also assessed. A was study performed in four hospitals related to $\mathrm{MOH}$ in Egypt.The results revealed that most of head nurses $(60 \%)$ have a high job stress level in terms of: work environment stressors, lack of organizational support, work and education stressors, staff nurse's stressors, material stressors, work satisfaction, and achievement stressors. Also study showed that the high percentage of head nurses (83.3\%) had lowjob performance, and there was no significant correlation between level of stress of head nurses and their job performance ${ }^{(7)}$.

In accordance with the aforementioned studiesa study examined also the impact of work - related stress on registered nurses' performance in Katutura State Hospital in Windhoek, Namibia. The researchers 
found that about $95 \%$ of nurses exposed to the high level of stress. And, they found that work load, staff shortage, lack of participation in decision making, and bad relations with colleagues, lack of training on stress management, absence of leisure time to reduce stress, lack of managerial support, and bad working conditions are the most common stressors $^{(9-11)}$.

In Jordan, astudy aimed to assess the relation between job stress that resulting from (family factors, economic factors, peer competition, job difficulty and organizational climate) and nursing performance in King Abdullah Hospital in Irbid, Jordan. The results showed that the organizational climate is the major stressor. Family factors not consider a stressor according to the nurses and affect their job performance, but performance affected by other four stressors as the follow: organizational climate, then economic factors,

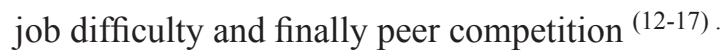

The nursing students perceived stress in clinical training was examined. A Jordanian study aimed to assess the relation between nursing students perceived stress in clinical training and their clinical performance, and relation between stress related factors and clinical performance. The researchers conclude that students perceived stress in clinical training is negatively correlated with their clinical performance, and also the stress related to the lack of knowledge and skills, and that related to patient's care are negatively correlated with clinical performance. The study also revealed that the major sources of stress among students are:student's assignments, patient care, teacher and nursing staff, and lack of knowledge and skills, respectively. The mean perceived stress is $(45.9 \%)$, and mean of student's clinical performance is $(73.4 \%)^{(18)}$.

In Greece, a study examined the relation between nurse's work stress, caring behaviors of patients, and nurse's health-relatedquality of life. According to the study, the most common stressors for nurses were: limited knowledge in dealing with death and dying, unable to aid patients and families' emotional needs, conflict with supervisor, and uncertainty with therapeutic effect of management.Also, there is a negative correlation between work stress and all dimensions of caring behaviors inventory. There are certain stress factors that are independent predictor for each CBI dimensions, such as: conflict with co-worker is independent predictor for affirmation of human presence, and associated with mental health. Discrimination stressor is predictors for quality of life (physical health) ${ }^{(5)}$.

\section{Conclusion}

Nursing is one of the riskiest profession, nurses exposed to the different stressors in their work area, thosestressors related to different causes, such as: work environment, co -worker relations, conflict with supervisor, work load, painful situations, lack of knowledge and skills among nurses, lack of support. There is a negative relationship between nursing occupational stress and their job performance, job satisfaction, physical and mental health, quality of life, and positive relationship between job stress andnurses'burnout.

Conflict of Interest: No conflict of interest.

Ethical Clearance: Taken fromPrincess Salma Faculty of Nursing, AL al-Bayt University ethical committee.

\section{Source of Funding: Self.}

\section{References}

1. Rajabi, B ;Hashtchin, $\mathrm{T}$; \&Hatami,M. A Comparative Study of Job Performance, Occupational Stress and General Health in Nurses of Psychiatric and Emergency Department. Annals of Medical and Health Sciences Research 2018; 8:198 -203.

2. Deng,J ; Guo,Y ; Ma,T ; Yang,T ; \&Tian,X. How job stress influences job performance among Chinese healthcare workers: a cross-sectional study. Environmental Health and Preventive Medicine 2019; 24:1-11.

3. Safarpour,H ; Sabzevari, S; and Delpisheh, A. A Study on the Occupational Stress, Job Satisfaction and Job Performance among Hospital Nurses in Ilam, Iran. Journal of Clinical and Diagnostic Research 2018; 12:1-5.

4. Mokhtar,K ; El Shikieri,A ; Taha,M ; \&Rayan,A. The Relationship between Occupational Stressors and Performance amongst Nurses Working in Pediatric and Intensive Care Units. American Journal of Nursing Research 2016; 4:34 - 40. 
5. Sarafis,P ; Rousaki,E ; Tsounis, A ; Malliarou, M ; Lahana ,L ;Bamidis,P ; Niakas,D ; \& Papastavrou, E. The impact of occupational stress on nurses' caring behaviors and their health related quality of life. BMC Nursing 2016; 15:1 - 9.

6. Adib - Hajbaghery, M ;Khamechian, M ; \&Alavi, N. Nurses' perception of occupational stress and its influencing factors: A qualitative study. Iranian Journal of Nursing and Midwifery Research 2012; $17: 352-359$.

7. El-Gabbour,G ; Afifi,F ; Fahmy,M ; \& El- Sayed, N. The Relationship Between Job Stress and Head Nurses Job Performance. Port Said Scientific Journal of Nursing 2015; 2:156 - 173.

8. Suliman, M.,Almansi SH.,Mrayyan, M, \& ALBashtawy M. Leadership styles And their effect on nurse turnover. Nursing management 2020.

9. Akweenda, $\mathrm{F}$;Cassim, $\mathrm{N}$; \&Karodia, A. Investigating Work Related Stress And Its Impact On The Performances Of Registered Nurses Employed At Katutura State Hospital In Windhoek, Namibia. Arabian Journal of Business and Management Review 2016; 5:50 - 78.

10. ALBashtawy, M. \& Aljezawi, M. Emergency nurses' perspective of workplace violence in Jordanian hospitals: A national survey. International emergency nursing 2016;24:61-65.

11. Al-ghzawi. H, ALBashtawy, M., Azzeghaiby,S, .\&Azzeghaiby,I. The Impact of Wars and Conflicts on Mental Health of Arab Population. International Journal of Humanities and Social Science 2014; 6:237-242.
12. Al -Khasawneh, A.,\&Futa, S. The Relationship between Job Stress and Nurses Performance in the Jordanian Hospitals: A Case Study in King Abdullah the Founder Hospital. Asian Journal of Business Management 2013; 5:267 -275.

13. ALBashtawy, M. Workplace Violence against Nurses in Emergency Department in Jordan. International Nursing Review 2013; 60:550-555.

14. ALBashtawy, M., Al-Azzam M., Rawashda, A., Batiha, A., Bashaireh, I., Sulaiman, M. Workplace Violence towards Emergency Department Staff in Jordanian Hospitals: A cross Sectional Study. Journal of Nursing Research 2015; 23:75-81.

15. HaneenFalahSalame and Mohammed AL Bashtawy. "Managing Workplace Stress among Health Care Providers". EC Psychology and Psychiatry 2019; 8:792-794.

16. Abdullah Al Kazaleh and Mohammed AL Bashtawy. "Therapeutic Communication Skills in Nursing Education and Practice". EC Psychology and Psychiatry 2019; 8:01-04.

17. Nora Mohammed Howeri and Mohammed ALBashtawy. "Workplace Stress among Nurses in Intensive Care Units". EC Psychology and Psychiatry 2020; 9:01-03.

18. Akhu-Zaheya,L ; Khater, W ; \&Shaban,I. Nursing Students Perceived Stress and Influences in Clinical Performance. International Journal of Advanced Nursing Studies 2015; 4:44-48. 